\title{
UAS-based automatic bird count of a common gull colony
}

\author{
G. J. Grenzdörffer ${ }^{\text {a }}$
}

${ }^{a}$ Rostock University, Chair for Geodesy and Geoinformatics, 18059 Rostock, Germany - goerres.grenzdoerffer@unirostock.de

Commission I, ICWG I/5

KEY WORDS: UAS, 3D-Point Cloud, Image Classification, DEM

\begin{abstract}
:
The standard procedure to count birds is a manual one. However a manual bird count is a time consuming and cumbersome process, requiring several people going from nest to nest counting the birds and the clutches. High resolution imagery, generated with a UAS (Unmanned Aircraft System) offer an interesting alternative. Experiences and results of UAS surveys for automatic bird count of the last two years are presented for the bird reserve island Langenwerder. For 2011 1,568 birds $( \pm 5 \%$.) were detected on the image mosaic, based on multispectral image classification and GIS-based post processing. Based on the experiences of 2011 the results and the accuracy of the automatic bird count 2012 became more efficient. For 20121,938 birds with an accuracy of approx. $\pm 3 \%$ were counted. Additionally a separation of breeding and non-breeding birds was performed with the assumption, that standing birds cause a visible shade. The final section of the paper is devoted to the analysis of the 3D-point cloud. Thereby the point cloud was used to determine the height of the vegetation and the extend and depth of closed sinks, which are unsuitable for breeding birds.
\end{abstract}

\section{Introduction}

\subsection{Motivation and study area}

The standard procedure to count birds is a manual one. However a manual bird count is a time consuming and cumbersome process, requiring several people which go from nest to nest counting the birds and the clutches. Double counts or no counts cannot be avoided. The average accuracy is somewhat between $80-90 \%$. For sure however, the birds receive additional stress during the breeding process. Manual counts, based on estimation and extrapolation are generally subject to even greater inaccuracies. These depend on the species to be examined, the number of individuals, the observer and the observation point. Here over- or underestimates of $25 \%$ are not uncommon (e.g. Bibby et al., 1995, Kulemeyer et al., 2011) with accumulations of 2,000 individuals or more.

Alternative procedures, e.g. using remote sensing or image analysis techniques were not available in the past, because the necessary ground sampling distance of $2 \mathrm{~cm}$ or better to clearly detect birds could not be obtained with a common aerial survey. Furthermore aerial surveys of such small areas are often not economically feasible. Since a few years UAS offer an interesting alternative. Other studies, for example Sardà-Palomera et al. (2012), Watts et al., (2010) have shown that in principle it is possible to observe birds with UAS. However, these two studies were limited to the use of UAS and the evaluation of image acquisition, the bird count has been done manually.

The study area is the approximately 25 ha bird reserve island Langenwerder. The area located north of the island of Poel and is under protection since 1903. The island is mostly covered with grass and reeds and nearly free of trees. The island is a nature reserve and closed to the public. To protect the nesting birds during the main breeding season an electric fence set up in the south of the island, to keep foxes and wild boars away from the island.
The predominant bird of the island is the common gull (Larus canus). The island is home to the largest colony of gulls along the Baltic Sea coast, but with a deceasing tendency. While there were 3,000 breeding pairs in 2002, the number has declined in recent years to about 1,500 breeding pairs. Among other species of breeding birds, the island an important resting place for migratory birds, such as Brent geese and Lemikolen. An adult Common Gull has a body length of 40-45 cm and a wingspan of $100-130 \mathrm{~cm}$. Seen from above, the common gull typically has a white head, a light gray plumage and gray to white tail feathers.

\subsection{UAS and birds?}

Prior to the first flights in May 2011 the big question was how do the birds react to a UAS? Strong disturbances of the birds are known from low flying manned airplanes used for sea bird surveys, e.g. Kulemeyer et al., (2010). Other authors report a minimum flight height of $300-400 \mathrm{~m}$ above ground for undisturbed aerial bird surveys.

Fortunately the birds did not show any panic or escape behavior against the electrically powered multicopters (Falcon 8, MD 4 1000). At distances of $15 \mathrm{~m}$ and more the birds just ignored the UAS. Not only the common gulls, but all birds on the island showed this behavior, see Figure 1

\subsection{UAS-aerial survey planning for bird count}

After the birds obvious ignorance to the UAS, the next was question, what altitude or GSD is necessary to recognize the birds one hand and on the other hand to ensure maximum ground coverage per image keeping the limited flight time of about 15 minutes Falcon 8 in mind. One assumption was that a bird should be covered with about 20 - 30 pixels to make sure it can identified safely on the digital images. This assumption was empirically tested. The determined optimal flight altitude for the $40-45 \mathrm{~cm}$ birds was $50 \mathrm{~m}$ with an associated GSD of about 1.6 $\mathrm{cm}$. 


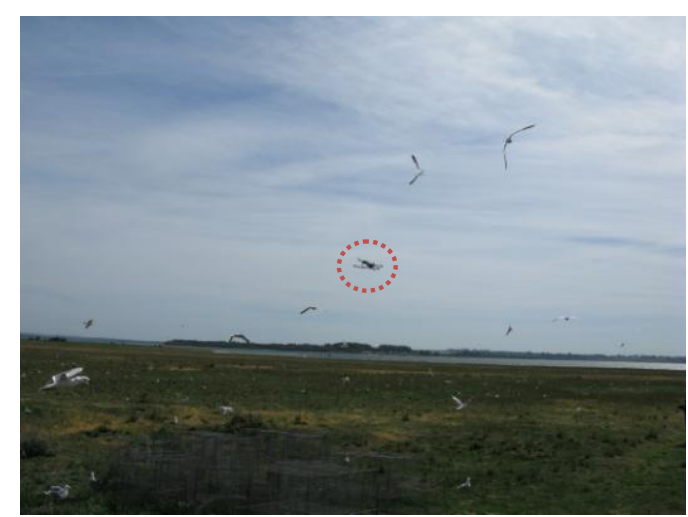

Figure 1. Birds show no disturbance by UAS (Falcon 8)

In the photo flight planning a $80 \%$ endlap and a $60 \%$ crosslap was chosen. The large crosslap should ensure that wind gusts, which can cause uncontrollable rolling movements do not lead to gaps in the image mosaic. Additionally the large overlap enhances the georeferencing procedures and enables the creation of a true orthophoto. During an aerial survey the UAS will usually stop several seconds to trigger a near nadir image. After it has been found that the so-triggered images are not so much more vertical, especially under windy conditions, this function was disabled. Now the images are triggered continuously at a predefined time interval, according to the altitude and the air speed of the UAS. In the two years, two different UAS were used; their technical parameters are summarized in Table 1 below.

\begin{tabular}{|l|l|l|}
\hline & $\begin{array}{l}\text { Falcon 8* } \\
(\mathbf{2 0 1 1})\end{array}$ & $\begin{array}{l}\text { MD4-1000** } \\
\text { (2012) }\end{array}$ \\
\hline Number of rotors & 8 & 4 \\
\hline Max. payload & $400 \mathrm{~g}$ & $1.200 \mathrm{~g}$ \\
\hline Max. take off weight & ca. $2 . \mathrm{kg}$ & ca. $5 \mathrm{~kg}$ \\
\hline $\begin{array}{l}\text { Flight time (with normal } \\
\text { payload) }\end{array}$ & ca. $15 \mathrm{~min}$ & ca. $30 \mathrm{~min}$ \\
\hline Camera stabilisation & Yes (2-axes) & Yes (2-axes) \\
\hline Camera & Sony NEX5 & $\begin{array}{l}\text { Olympus PEN } \\
\text { E2 }\end{array}$ \\
\hline Camera Resolution (Pixel) & $4592 \times 3056$ & 3000 x 4000 \\
\hline
\end{tabular}

Table 1. UAS used for aerial surveys of bird reserve island Langenwerder 2011 and 2012

* Ascending Technologies (http://www.asctec.de/

** Microdrones GmbH (http://www.microdrones.com)

\subsection{Aerial surveys 2011}

In 2011, two flights were carried out on parts of the island on $30 / 05 / 2011$. Technical problems during the first flight led to poor UAS flight performance and unsystematic images were triggered. The second flight went smoothly and 50 images were available for further processing. A classic aerial triangulation was not possible due to the lack of control points, as the island could unfortunately not be accessed for control point measurements. An aerotriangulation without ground control was also not feasible because the GPS of the UAS with approximately \pm 2-3 meters accuracy are too inaccurate for standard photogrammetric software tools such as ERDAS LPS.

Finally, a different approach was chosen, which is based on commercial panorama software. After various experiments with open source products and freely usable software, the choice finally fell on the software Autopano Giga 2.5. This software allows for multiple locations and also allows to correct some wrong assignments manually. During mosaicking it has been found that the radial distortion, which is quite significant at the wide-angle lens of the Sony NEX5, cannot be modeled adequately by the software. Consequently, the radial distortion was corrected with the software ImageIron and the stitching and mosaiking was done with the corrected images in Autopano. The resulting color balanced mosaic has 20,520 x 19,297 pixels and covers an area of approximately 4.4 hectares. Finally, the image mosaic was roughly georeferenced using 4 points acquired from existing orthophotos. Due to the flat terrain the residuals are within $1 \mathrm{~m}$.

\section{Automatic bird recognition and bird count 2011}

The recognition of the birds that was done by $\mathrm{P}$. Schneider (2011) as part of his bachelor thesis. Thereby a simple strategy has been pursued, which is based primarily on the spectral properties of the seagulls. Ultimately the birds are almost the only white elements in the pictures with their white heads and light gray body. A more complex object-oriented approach was deliberately omitted, since the image data set is quite large and that can result in long processing times. Only in a second stage, size and shape play a role. In particular, the data analysis is as follows:

\section{Supervised classification:}

As the seagulls have a white head and a light gray plumage, they are spectrally easily identifiable in the color images. With the ArcGIS 10 software a supervised multi spectral classification with a total of 7 classes was conducted. The resulting grid with the class "birds" (52,488 objects) was transferred into vector form.

\section{Size-based selection of birds}

At the beach there was a spectral overlap between the birds and the bright sand. Since no birds are nesting on the beach, the beach area was digitized and the classified objects in that area were eliminated (11,157 objects remain). The area of the "bird" objects was calculated and added as a new attribute to the polygons. Subsequently all objects whose surface area is less than $10 \mathrm{~cm}^{2}$ (e.g. small bright stones, etc.) were removed. Large objects, for example Mute swans were also been removed by a size threshold of $>2.000 \mathrm{~cm}^{2}$. Due to the change in color, light head, gray plumage and bright tail feathers of birds, a single bird was often classified as two closely spaced bird objects. To merge the two parts, neighbouring polygons whose distance from one another is less than $24 \mathrm{~cm}$ were united. Finally all remaining objects with less than $20 \mathrm{~cm}^{2}$ were removed, see figure $2 a-b$.

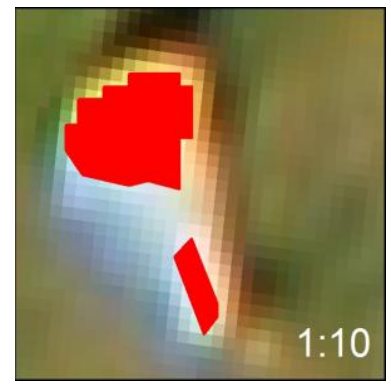

Figure 2a. bird object before aggregation

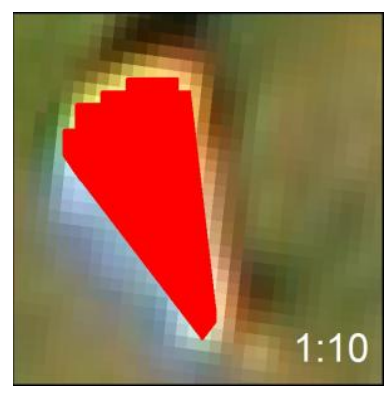

Figure 2b. bird object after aggregation 
As a result 1,568 birds were counted. The accuracy (over- and underestimation) was determined using visual counts against a defined section with 500 bird objects.

During the visual quality check of the 500 bird objects 477 gulls (95.4\%) could actually be verified. Thereby 65 objects were identified incorrectly as a bird and at the same time 42 birds were not classified as such. When counting by hand several main characteristic errors of the recognition of "bird" objects could be identified: incorrectly recognized objects were mainly pieces of wood, stones and locally bright spots in green spaces. In addition, "dark" and or birds in the shade of bushes were not detected. Birds too close together classified as one object. Also some birds in blurred image regions were not classified correctly. Main reasons for image blur was on the one hand the wideangle lens of the Sony NEX5 and on the other hand the stitching software that generated a blurred area around the seamlines of adjacent images.

\section{Automatic Bird recognition and Bird count 2012}

Building on the experience of 2011, in 2012 the study area could be extended by using the MD4-1000, which has a flight time of about 25 - 30 minutes per battery. Also the flight altitude above ground was slightly increased to $55 \mathrm{~m}$. An aerial survey of the relevant parts of the island could be carried out successfully on 25.5.2012 recording a total of 629 images. The external conditions were perfect, almost windless and cloudless sky. The aerial survey of the island was carried out by four individual flights to temporarily change the battery and to minimize the required time of flight by a clever choice of the starting points. To ensure that the camera does not stop to take images during the flight because of lack of electricity, the camera battery was changed between flights.

Accompanying the aerial survey some signalized control points were measured with a RTK GPS at one edge of the island. Since the birds were in the business of breeding, island could not be accessed for control point measurements. Thus, the ground control points mainly served to fit the block in terms of position and scale.

The photogrammetric data analysis was performed using the software Pix4D, which was used as a web service. The results of the photogrammetric data processing were a digital ortho photo, a digital surface model (DSM) and a 3D-point cloud. According to the report the position and height accuracy $(1 \sigma)$ at the five control points was approximately $5 \mathrm{~mm}$.

\subsection{Automatic bird recognition and bird count 2012}

The method of automatic bird count in 2012 is basically similar to the approach for 2011. Only the size of the filter to eliminate small misallocations and large objects were changed slightly. The "bird census" for 2012 showed a total of 1,945 birds, see Figure 3. The classification quality was validated with 605 objects. There were 560 items verified as birds. On closer inspection 45 objects turned out to not be a bird, but as something else. At the same time 31 birds were not recognized as such. That means $97.6 \%$ of the birds were detected. The increase in the classification accuracy in 2012, can be clearly attributed to the better image quality.

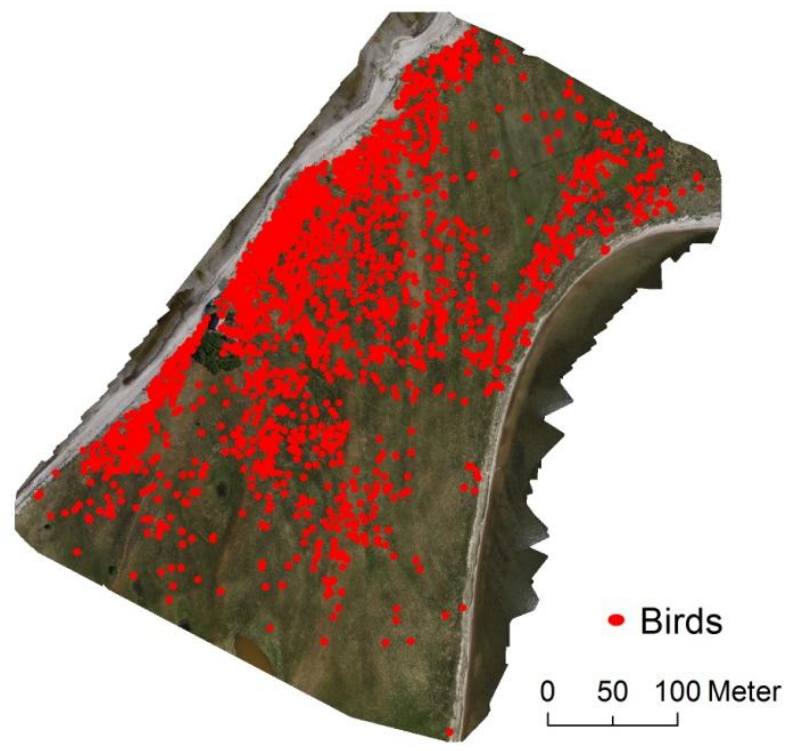

Figure 3. Identified bird objects (red dots) from UAS aerial survey of 25.5.2012 on the birds reserve island Langenwerder

\subsection{Identification of breeding birds}

For the bird census counting all individuals is an important factor. The number of clutches is of more interest to the ornithologists, than just the number of birds, because the average number of eggs per clutch is known and the reproduction potential is an important number. Since the size of the nest is not visible from the air - after all the birds sit on the nest, it is of great interest to determine at least the number of breeding pairs. The conducted aerial survey during the morning hours was basically at an optimal time, as in most breeding pairs, one partner at this time is out foraging for food. So the number of counted birds approximately matches with the breeding pairs. Visually the breeding birds can be distinguished from the standing birds. A closer inspection reveals that the standing birds produce a small shadow, as shown nicely in Figs 4a and 4c.

The direction and length of the shadow is determined by the position of the sun, resulting from the geographical position $\left(54^{\circ} 01\right.$ 'N, $11^{\circ} 29^{\prime} \mathrm{E}$ ) and the time (about 10:00 clock EST), as well as the size of the upright standing birds. Thus, the shadow falls from an elevation of about $40^{\circ}$ toward $290^{\circ}$ (WNW). With a bird size of about 30 to max. $40 \mathrm{~cm}$, the length of the shadow is $34-46 \mathrm{~cm}$. 


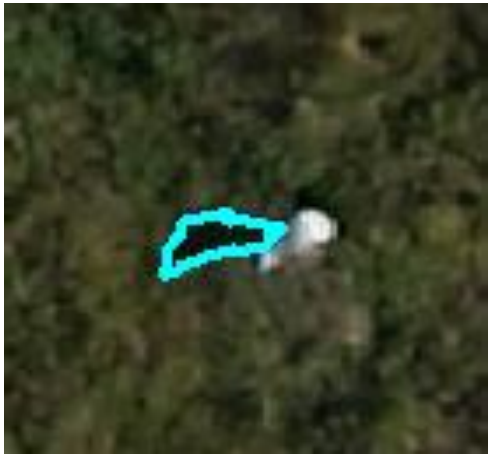

Figure 4a. correctly classified standing bird with shadow

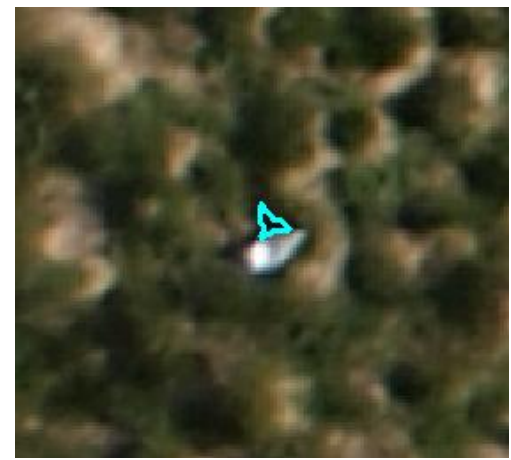

Figure $4 \mathrm{~b}$. incorrectly classified sitting bird (adjacent vegetation)

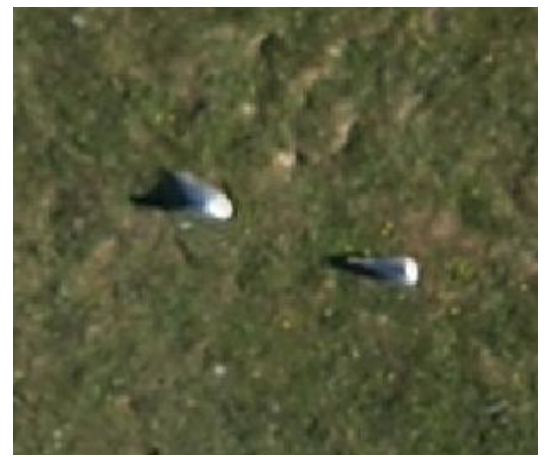

Figure 4c. incorrectly classified standing birds (Unfavorable orientation, ie, small shadow)
The dark shadow area can be easily classified and spectrally separated from the rest of the image. Around the birds a sectoral buffer was defined with a diameter of $40 \mathrm{~cm}$. The shadow mask was overlaid with the bird buffer zones (4,137 objects). It turns out that many wrong assignments have been eliminated in further processing steps. The errors in this initial step are due to the fact, that the vegetation (grassland) itself introduces many small shadow elements and furthermore birds like to breed in tall grass, which creates the shadows. A first area filter removes many small shadow elements that can occur next to breeding birds. Another filter eliminates shadow objects that are not adjacent to a bird, which means less than $15 \mathrm{~cm}$ from the bird centroid. A final filtering step selects those birds that are not in the tall grass $(>15 \mathrm{~cm})$. The grass height is determined from the point cloud (see section 6.1).

The dark shadow area can be easily classified and spectrally separated from the rest of the image. Around the birds a sectoral buffer was defined with a diameter of $40 \mathrm{~cm}$. The shadow mask was overlaid with the bird buffer zones (4,137 objects). It turns out that many wrong assignments could be eliminated in further processing steps. The errors in this initial step are due to the fact, that the vegetation (grassland) itself introduces many small shadow elements and furthermore birds like to breed in tall grass, which creates the shadows. A first area filter removes many small shadow elements that can occur next to breeding birds. Another filter eliminates shadow objects that are not adjacent to a bird, which means less than $15 \mathrm{~cm}$ from the bird centroid. A final filtering step selects those birds that are not in the tall grass $(>15 \mathrm{~cm})$. The grass height is determined from the point cloud (see section 6.1).

Finally, 54 birds could be identified that do not breed, but pursue other activities. A visual inspection revealed that the strategy was not really successful. Rather, the success rate was only about $74 \%$. Among others, one reason is birds often breed in the immediate vicinity to some higher grasses which cause shadows. At the same time several standing birds were also not recorded properly, e.g. because they stand with their longitudinal axis in east-west direction, so they only cast very small shadows, see figure $4 \mathrm{a}-\mathrm{c}$. As a conclusion perhaps $50-100$ birds are not in the business of breeding, so that the number of breeding pairs on Langenwerder in 2012 is about 1,850 - 1,900.

\subsection{Accuracy assessment}

Unfortunately, no census of the total Gull colony of the study area was carried out as an independent reference in the two years by the ornithological society Langenwerder e.V. Nevertheless some reference data is available for two small monitoring sites, which in 2012 host 40 (dune site) and 37 (grassland site) breeding pairs respectively. The comparison to the UASbased bird count is shown in table 2 .

\begin{tabular}{|l|l|l|}
\hline & Dune Site & Grassland site \\
\hline $\begin{array}{l}\text { Ornithological } \\
\text { reference }\end{array}$ & 40 & 37 \\
\hline Visual control & 42 & 36 \\
\hline Classification & $\begin{array}{l}\text { 43 and 2 gulls } \\
\text { correctly identi- } \\
\text { fied as standing } \\
\text { birds }\end{array}$ & $\begin{array}{l}\text { 37 birds, 32 cor- } \\
\text { rectly, plus 5 gulls } \\
\text { incorrectly identi- } \\
\text { fied as standing } \\
\text { birds }\end{array}$ \\
\hline $\begin{array}{l}\text { Difference Classi- } \\
\text { fication vs. Visual } \\
\text { control }\end{array}$ & 1 error (stone) & $\begin{array}{l}\text { 4 errors, ,dark“ } \\
\text { breeding birds } \\
\text { were not counted }\end{array}$ \\
\hline $\begin{array}{l}\text { Difference Classi- } \\
\text { fication vs. Orni- } \\
\text { thological refer- } \\
\text { ence }\end{array}$ & 3 & 1 \\
\hline
\end{tabular}

Table 2. Reference counts and classification accuracy

The visual count of the image data and the reference observations are almost identical (78 birds vs. 77 birds). In total the visual inspection shows a very high correlation with the automatic classification ( \pm 1 breeding bird). The automatic classification and shading analysis works very well in the dune test area. In tall grass the automatic classification is rather conservative, i.e. there are too few birds counted. The automatic classification of the shadow cast to identify standing birds does not really work in tall grass (which was also expected).

\section{SPATIAL DISTRIBUTION OF BIRDS}

The breeding places of the ground-nesting birds are not evenly spread throughout the island - which could not really be expected. Rather the mass of the birds reside on the western side, or nest on the levee (see Figure 3). The main reason for this behavior is probably that the prevailing westerly winds there can optimally reach under the wings of the birds and hence the energy consumption is minimal when starting. In the southeast of the island only a few birds can be observed, which is according to statements of local ornithologists due to higher vegetation. In the middle and in the north of the island relatively few 
birds are also observed. Reasons for these observations are most probable related to unfavorable breeding conditions.

According to the literature, the male bird chooses the nesting site, which is often at the same spot as in previous years, e.g. von Blotzheim and Bauer (2000). The nesting area should be as safe possible against terrestrial predators, weather and flooding. Usually the ground nests are located at places with little vegetation. Otherwise, ground nests may also be located in inaccessible places such as small islands, headlands, dams or quaking bogs.

The remote sensing data (orthophoto, DTM and the 3D point cloud) derived from the UAS delivers important site characteristics.

\subsection{Determination of canopy height from the 3D point cloud}

The height of the vegetation cannot be determined directly from the digital surface model without a reference DTM. Much more interesting is the $3 \mathrm{D}$ point cloud. As shown in profile (Figure 5) the canopy surface is not represented by a clear boundary, but by a fringe with a certain height. The height of the fringe (= canopy) varies, depending on the height of the grasses, sedges or small bushes.

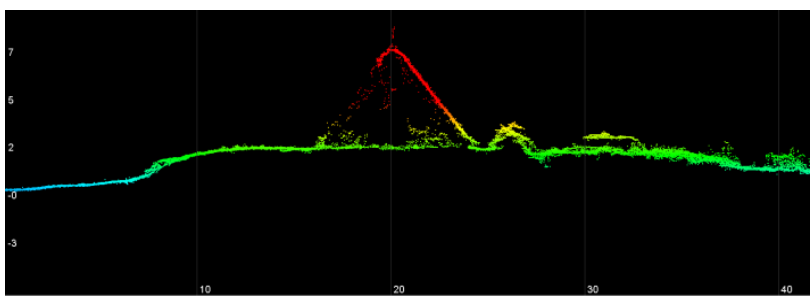

Figure 5. $2 \mathrm{~m}$ wide and $42 \mathrm{~m}$ long cross section through 3Dpoint cloud (from left to right) (beach - ornithological station shed - shrubs)

To determine the height of the fringe or the vegetation, the $3 \mathrm{D}$ point cloud was analyzed with the software LAStools / lascanopy. The average point density of the point cloud is 215 points $/ \mathrm{m}^{2}$ and the average point spacing is $6.8 \mathrm{~cm}$. Thus, compared with conventional laser scanners the point density derived from the UAS imagery is very high. In principle the point density should be high enough to describe the irregular canopy surface. For grid with a cell of $0.5 \mathrm{~m}$ the minimum, average, maximum and standard deviation of points per grid cell were calculated. Since the extreme values (minimum and maximum) may be erroneous, due to single outliers, in this case two times the standard deviation represents best the actual canopy height (Figure 6).

As mentioned above, favorable locations of the open nests are in low vegetation. Figure 7 shows the distribution of plant height at each bird locations.

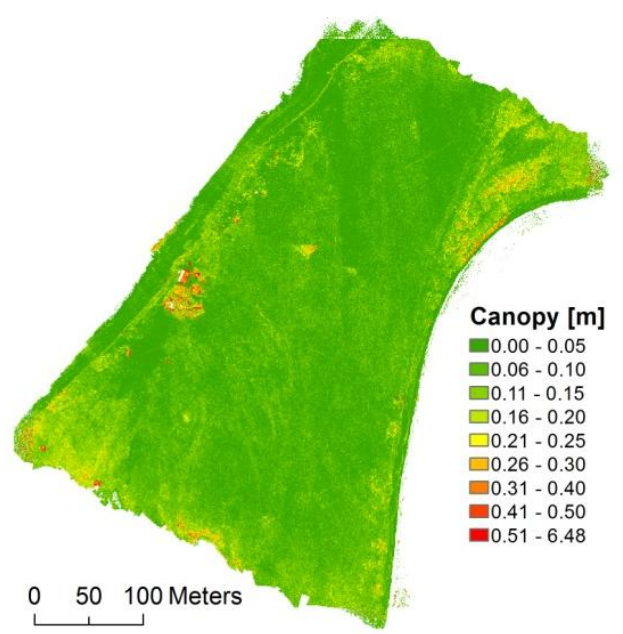

Figure 6. Calculated canopy height from the 3D point cloud

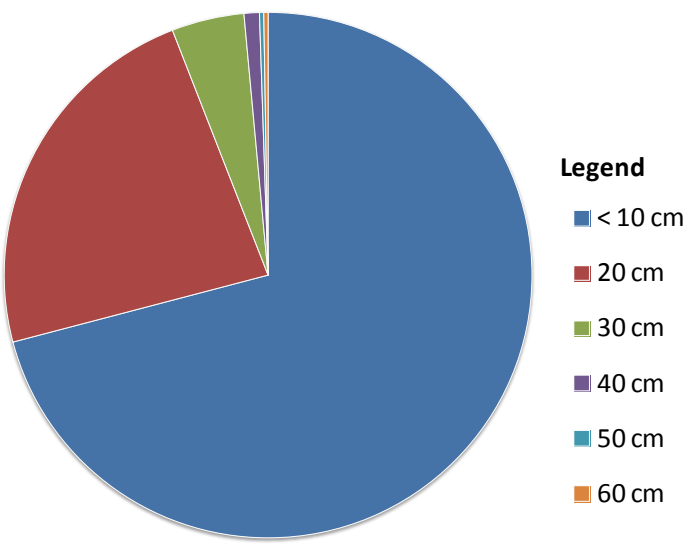

Figure 7. Vegetation height adjacent to the birds

\subsection{Geomorphology and bird distribution}

The overall very flat island Langenwerder with an average height of only $1.09 \mathrm{~m}$ above the sea level is constantly "in motion" because it is constantly eroded on one side and "new" sand is deposited on the other side of the island. During the formation of the island after the last glaciation, prevailing southerly currents and winds formed the beach ridges that run from NNE to SSW, Lemke, 2004. This can be observed on the digital terrain model very well, see Figure 8

The current coastal forming processes are somewhat different to former times. Firstly, the main wind and the main flow direction have changed to west, so that the island grows on the southwest side. On the other hand, the island is under pressure on its northwest side, especially during storm weather conditions. This material is shifted to the north-east side of the island and increases the headland at that place.

As mentioned, birds seek their breeding sites in dry, non-flood endangered areas. In order to verify this closed sinks were calculated from the DEM. In these areas heavy rainfall may cause wet grounds or local flooding. On the other hand, at high tide the water level may raise up to $70 \mathrm{~cm}$ above normal within hours and cause local flooding, Figure 9. 


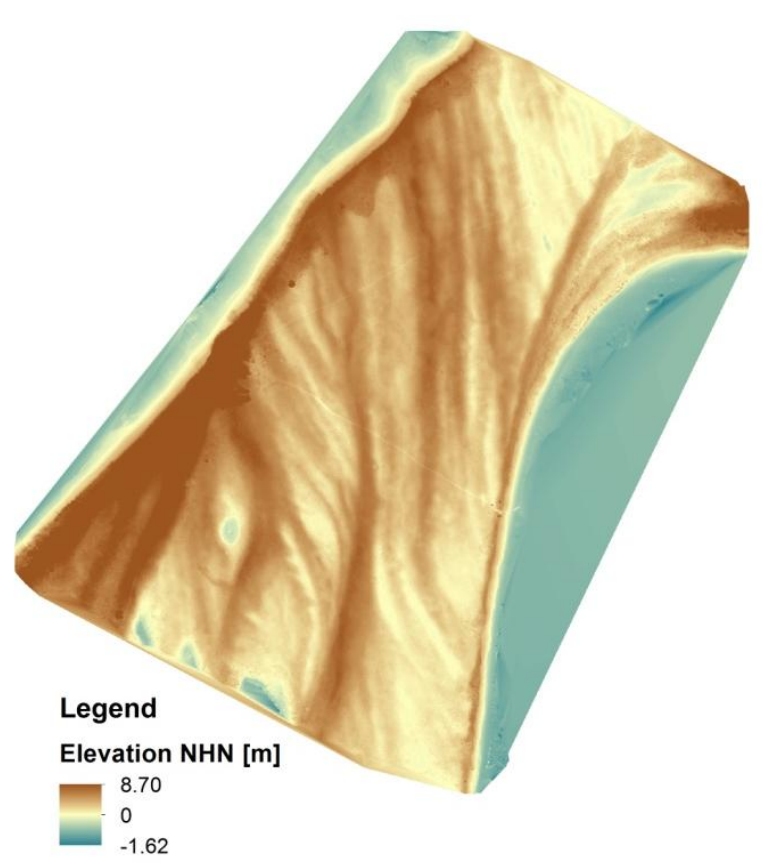

Figure 8. DSM of the bird reserve island Langenwerder

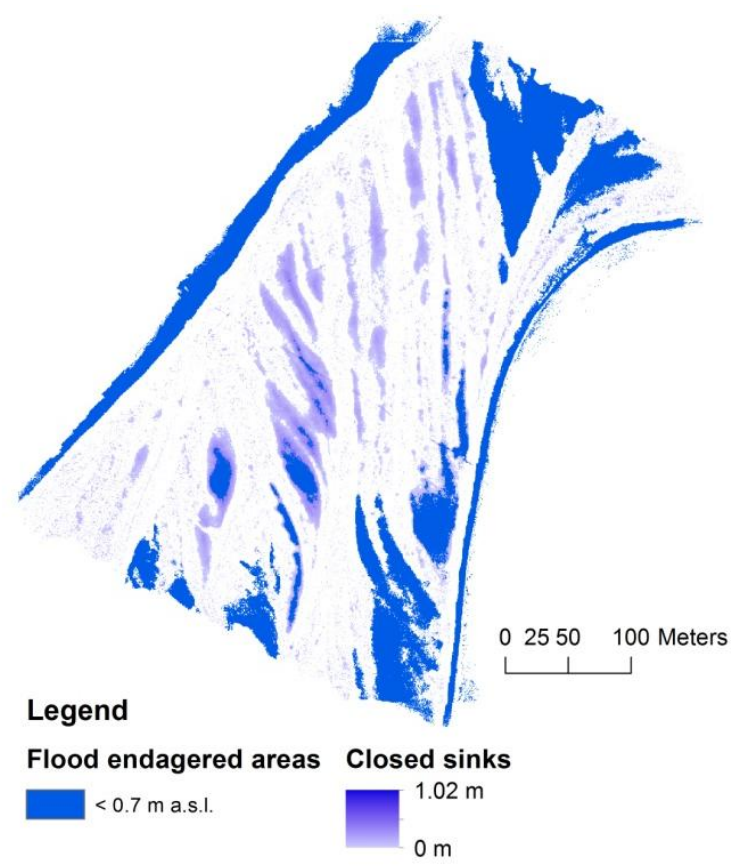

Figure 9: Flood endangered areas and closed sinks derived from the DTM

\subsection{Summary and Outlook}

In this paper it was demonstrated that in principle it is possible to count birds using UAS with great reliability. However, this methodology does not necessarily apply to other bird species, as the examined gulls provide very good contrast to its surroundings.

The bird count with the UAS is to be continued in the current year. Special focus will be given on the study of the nest site fidelity.

\section{References}

Bibby J. C., Burgess N. D., Hill D. A., 1995. Methoden der Feldornithologie; Bestandserfassung in der Praxis. Neumann Verlag $\mathrm{GmbH}$

Kulemeyer, C., Schulz, A. Weidauer, A., Röhrbein, V., Schleicher, K. Foy, T., Grenzdörffer, G. and Coppack, T., 2011. Georeferenzierte Digitalfotografie zur objektiven and reproduzierbaren Quantifizierung von Rastvögeln auf See,- Vogelwarte 49, 2011: S. $105-110$

Lemke, M., 2004. Geodatenerfassung and -fortführung für landschaftsökologische and naturschutzkundliche Aufgaben am Beispiel der Insel Langenwerder.- unveröff. Diplomarbeit TU Berlin, $121 \mathrm{~S}$.

Sardà-Palomera, F., Bota, G., Viñolo, C., Pallarés, O., Sazatornil, V., Brotons, L., Gomáriz, S. And Sardà, F., 2012), Fine-scale bird monitoring from light unmanned aircraft systems. Int. Journal of avian science (Ibis), 154: S. 177-183.

Schneider, P., 2011. Hochmoderne luftbildgestützte Zählung von Vögeln mit Hilfe eines Multicopters - am Beispiel einer Sturmmöwenkolonie auf der Vogelinsel Langenwerder, Bachelorarbeit, Universität Rostock 39. S.

von Blotzheim U.N. and Bauer, K.M., 2000. Handbuch der Vögel Mitteleuropas, Band 8/I, Charadriiformes (3. Teil), Schnepfen-, Möwen- and Alkenvögel, S. 440-493.

Watts, A. C., Perry, J. H., Smith, S. E., Burgess, M. A., Wilkinson, B. E., Szantoi, Z., Ifju, P. G. and Percival, H. F., 2010. Small Unmanned Aircraft Systems for Low-Altitude Aerial Surveys. The Journal of Wildlife Management, 74: 1614-1619. 